\title{
Industrial Agglomeration Analysis Based on Spatial Durbin Model: Evidence from Beijing-Tianjin-Hebei Economic Circle in China
}

\author{
Lu-Hui Gao, Guo-Qing Wang, and Jing Zhang \\ Anhui University of Finance and Economics, Bengbu, Anhui 233030, China \\ Correspondence should be addressed to Jing Zhang; zhangjingseuc@163.com
}

Received 4 July 2021; Accepted 22 July 2021; Published 27 July 2021

Academic Editor: Muhammad Javaid

Copyright (C) $2021 \mathrm{Lu}-\mathrm{Hui}$ Gao et al. This is an open access article distributed under the Creative Commons Attribution License, which permits unrestricted use, distribution, and reproduction in any medium, provided the original work is properly cited.

\begin{abstract}
Based on the data of Beijing-Tianjin-Hebei Economic Circle from 2010 to 2019, this paper uses the spatial Durbin model to empirically analyze the impact of financial development and technological innovation on industrial agglomeration. The following are the conclusions of this study: (1) financial development has a positive effect on industrial agglomeration; however, a significant difference exists in the weight effect of the geographic distance matrix compared to the weight of the economic distance matrix; (2) in the spatial Durbin model with two matrix weights, technological innovation has a significant positive effect on industrial agglomeration; and (3) in the spatial Durbin model with two matrix weights, the interaction has a significant negative effect on industrial agglomeration. Therefore, the government should further implement the coordinated development strategy, promoting regional technological innovation for a long time to realize its integration with financial development.
\end{abstract}

\section{Introduction}

The spillover effect of technological innovation and financial development on industrial agglomeration is an important problem. As a major national strategic development area, the continuous progress of the Beijing-Tianjin-Hebei region can effectively improve China's industry. We need to vigorously develop industrial clusters to promote product technology innovation [1]. The industrial agglomeration in this region should use both finance tools and new technology. Therefore, it is indispensable to optimize the urban structure and industrial layout. The impact mechanism of innovation on industrial agglomeration can be described as follows: the financial system improves the competitiveness of regional industries by mobilizing funds. The financial system also promotes the development of emerging industries by providing diversified financial services. Technology R\&D and introduction can increase the intensity of technological innovation, which is conducive to regional technology integration and cooperation.
The research of industrial agglomeration began at the end of the nineteenth century. Marshall put forward two important concepts of industrial agglomeration in 1890: internal economy and external economy [2]. Since then, academia has carried on a thorough discussion of this question. At first, there are the following studies on industrial agglomeration promoting economic development. Crozet and Koenig hold the view that the regional agglomeration of economic activities can significantly stimulate the improvement of the level of economic development. If this effect is more obvious, it will cause the degree of industrial equilibrium to be more affected [3]. Groot et al. found that the industrial agglomeration in promoting economic development has a life cycle. With the change of economic development level, the economic effect of industrial agglomeration will change accordingly $[4,5]$. $\mathrm{Hu}$ and Nie believed that the continuous emergence of the agglomeration effect will promote the industry by scientific and technological innovation [6]. Tang et al. found a highly spillover effect between manufacturing agglomeration and 
economic growth rate [7]. Zhao et al. found that the spillover effect of the industry can raise the level of regional innovation to a new level [8]. Gehrig chose the empirical investigation method and uses market friction theory as the theoretical support to comprehensively introduce industrial upgrading [9]. Christopoulos and Tsionas learned through surveys that financial support increases the improvement level [10]. Palmberg believed that, with the optimization of the communication technology system, financial support for the development of the real economy is increasing [11]. The attitude held by Michetti is that financial progress needs to meet certain prerequisites, namely, industrial development. In addition, the spillover effect is significant industrial growth [12]. The view held by $\mathrm{Li}$ et al. is that financial support can help enhance the level of industrial agglomeration, and the realization of this goal requires the help of the transmission mechanism established by technological innovation, which will ultimately stimulate the increase in total factor productivity, transformation, and spillover [13]. $\mathrm{Si}$ and Zhang took China's provincial capital cities as the survey subjects. After analyzing their panel data, they found that there are two basic indicators that have a positive spillover effect with economic development, namely, the expansion of financial output and the completion of industrial structure. In addition, they also pointed out that the positive spillover exists between the financial value and economic [14]. Zhang and $\mathrm{Yu}$ proved that the driving force of regional financial agglomeration comes from two aspects: urbanization roads and industrial structure upgrading [15]. Muller believed that producer services can help enterprises to influence each other in innovation, strengthen the knowledge spillover effect, and form an innovation drive for economic growth [16]. Kesidou and Romijn took the software industry cluster as the research object and found that enterprise innovation performance promotes regional technology spillover effect, which has an impact on industrial cluster [17]. Hornych and Schwartz used the number of patent applications to measure the ability of technological innovation. They analyzed the inverted U-type relationship between technological innovation and industrial agglomeration in East Germany by constructing an econometric model [18]. The survey by Knoben showed that the effect of technological innovation depends on the type of industry of the company on industrial agglomeration by improving enterprise productivity [19]. Cai and Wang hold the view that technological innovation is a powerful means for the smooth transfer of industries, which can significantly increase the productivity of industrial agglomeration [20]. $\mathrm{Wu}$ and Deng selected the Yangtze River Economic Belt as the survey object, selected its panel data, and investigated the impact mechanism of technological innovation in depth. They put forward the following viewpoints that technological innovation is of great help to the improvement of green total factor productivity, which has made great contributions to urban economic development, especially for the Yangtze River Economic Belt [21]. Baptista believed that geographic agglomeration is easy to produce knowledge spillover in the agglomeration area and promote industrial development [22]. Amiti through the analysis of interregional industrial agglomeration found that it can enhance regional innovation level by building an innovation environment and saving innovation cost [23]. Mukim thought that industrial agglomeration enjoys an obvious positive impact on the number of patent production (i.e., technological innovation) [24]. Du et al. used panel data of Yangtze River Delta and Beijing-Tianjin-Hebei Economic Circle to conclude that manufacturing industry agglomeration, as well as the market concentration of these two economic circles, has improved regional innovation ability through the innovation environment [25]. Ma and Hofmann tested the relationship by SDM between population and air quality [26]. Hao and Chen expressed a personal suggestion that both industrial agglomeration and technological innovation can contribute to economic growth [27]. Dong et al. used SDM to indicated a strong spatial spillover effect and autocorrelation and clustering characteristics appear in air pollution [28]. Wang and Zheng believed that the industrial development of some economic circles in China has entered the era of industrial chain with the diffusion of innovation [29].

The recent research also makes an empirical analysis based on the threshold effect. But some studies only involve two aspects of the impact on industrial agglomeration, namely, financial development and technological innovation, and a few studies consider the interaction between the two and industrial agglomeration. What makes this subject unique is that it fully analyzes the relationship between financial development and technological innovation and industrial agglomeration. Meanwhile, due to China's economic transformation and the shift of economic target, more scholars focus on the Yangtze River Economic Belt, Guangdong-Hong Kong-Macao, and other economic circles, while the research on Beijing-Tianjin-Hebei Economic Circle is relatively less.

In this context, the subject is based on two matrix weights, sets the Beijing-Tianjin-Hebei Economic Circle as the survey object, and creates a spatial measurement model that combines the interaction of finance and technology with each other. This paper will use the data of Beijing-TianjinHebei Economic Circle from 2010 to 2019 to empirically analyze the impact of financial development and its interaction on industrial agglomeration.

\section{Research Design}

\subsection{Variable Selection}

2.1.1. Explained Variable. Industrial agglomeration $(Y)$ is chosen as the explained variable. In the past empirical studies, the main factors related to industrial agglomeration are industrial concentration and location entropy. Currently, the Beijing-Tianjin-Hebei region is in a critical period of industrial structure upgrading and adjustment. Therefore, we applied the method created by Lian and Zhou to know the level of industrial agglomeration by using the density quotient of industrial enterprises [30]. Industrial added value reflects the scale of industrial enterprises and their production and operation 
levels. Therefore, this paper chooses the contribution value of industrial added value to GDP as the explained variable.

2.1.2. Explain the Variables. The explanatory variables were financial development $\left(X_{1}\right)$ and technological innovation $\left(X_{2}\right)$. When researchers in different countries around the world determine the level of scientific and technological innovation, they have selected two indicators as the evaluation reference standards, namely, the number of patent applications and the turnover rate of the technology market. This is mainly because design patents and utility model patents have no effect on economic development contact, only invention and creation can really promote industrial development and then affect economic development. Therefore, referring to empirical research, when measuring financial development $\left(X_{1}\right)$, the subject selected an indicator of the added value of the financial industry [31], and the set of scientific and technological innovation $\left(X_{2}\right)$ indicators was the number of patent applications [32]. This article also combines empirical cases to construct a spatial measurement model. In the process, two natural logarithms are set, namely, $X_{1}$ and $X_{2}$

2.1.3. Control Variables. Industrial agglomeration and financial development are inextricably linked with technological innovation. In addition, it also depends on the influence of many factors, such as policies and investment capital, but these effects are not the main problem of this paper. In order to control the independent factors, this thesis chooses government behavior, human capital, and capital investment level as the control variables. Because government public expenditure can have a great impact on industrial agglomeration, in the process of assessing government behavior $\left(Z_{1}\right)$, this topic selected an indicator as the contribution value of the public expenditure to local GDP. With the continuous advancement of industrialization and intellectualization, human capital is more reflected in the corresponding knowledge and skills. Thus, when assessing human capital $\left(Z_{2}\right)$ for this subject, an indicator is set as the proportion of college students in the local permanent population. The level of capital investment $\left(Z_{3}\right)$ is composed of two parts, namely, fixed capital investment and circulating capital investment. However, because working capital has more obvious regional liquidity, it cannot truly show the actual situation of capital investment in the region. Therefore, in the process of determining the level of capital investment in this topic, the selected indicator is the contribution value of fixed capital investment to the people's GDP. Table 1 details variable names and symbols.

2.2. Spatial Autocorrelation Test. First, we verify the autocorrelation of variables [33]. Therefore, this paper selects Moran's $I$ index and Gear's $C$ index. However, the $C$ of the gear does not have an advantage in using spatial weight, and its reliability is lower than Moran's I index. Therefore, when determining the spatial autocorrelation of the main variables, the subject chooses Moran's I index, industrial agglomeration $(y)$, financial development $\left(x_{1}\right)$, and technological innovation $\left(x_{2}\right)$ and then judges the significance of Moran's $I$ index by whether the $Z$ statistic is significant.

If it can describe Moran's I index significantly, it can vividly show the variables [32]; then, we can further set the weight matrix, construct the econometric model under different matrix weights, and analyze the direction and size of spatial correlation between variables. The formula for calculating Moran's I index:

$$
I=\frac{n}{S_{0}} \frac{\sum_{i=1}^{n} \sum_{j=1}^{n} w_{i j}\left(y_{i}-\bar{y}\right)\left(y_{j}-\bar{y}\right)}{\sum_{i=1}^{n}\left(y_{i}-\bar{y}\right)^{2}},
$$

where $w_{i j}$ represents the space weight matrix, which is generated between elements $i$ and $j, n$ is the total number of unit elements in the space, and $S_{0}$ is the sum of all spatial weights, $S_{0}=\sum_{i=1}^{n} \sum_{j=1}^{n} w i j$.

If the number of regions of $n$ can be high enough, Moran's $I$ index approximately follows the normal distribution, so it can be verified by the $Z$ test. The calculation formula of $Z$ statistic is as follows:

$$
Z_{I}=\frac{I-E[I]}{\sqrt{V[I]}}
$$

where this article uses I to represent the final result of Moran's $I$ index, the mean value of Moran's $I$ index is $E[I]=-(1 /(n-1))$, and the variance is $V[I]=E\left[I^{2}\right]-E[I]^{2}$.

2.3. Spatial Weight Matrix Building. Because Beijing and Tianjin are geographically adjacent and there are many cities adjacent to Hebei Province, the weights of geographic and economic distance are very important.

2.3.1. Geographical Distance Weight Matrix. The weight matrix of geographical distance takes the distance between different cities as the weight of spatial correlation analysis:

$$
W_{i j}^{1}= \begin{cases}\frac{1}{d}, & i \neq j, \\ 0, & i=j .\end{cases}
$$

In expression (2), $d$ as an important component represents the Euclidean distance of each city.

2.3.2. Economic Distance Weight Matrix. The economic distance weight matrix is representative of the provincial spatial weight matrix, and its production premise is economic distance, which can use the output value of different industries in different cities as the weight of spatial correlation analysis:

$$
W_{i j}^{2}=\left\{\begin{array}{l}
\frac{1}{\left|\overline{Y_{i}}-\overline{Y_{j}}\right|}, \quad i \neq j, \\
0, \quad i=j .
\end{array}\right.
$$


TABLE 1: Variable name, symbol, and description.

\begin{tabular}{lccc}
\hline Variable name & Index & Symbol & Description \\
\hline Explained variable & Industrial agglomeration & $Y$ & Industrial added value/GDP \\
Explanatory variable & Financial development & $X_{1}$ & Financial added value \\
& Technological innovation & $X_{2}$ & Number of invention patent applications \\
Control variable & Government action & $Z_{1}$ & Public expenditure/GDP \\
& Human capital & $Z_{2}$ & Number of college students/resident population \\
& Capital input level & $Z_{3}$ & Fixed capital investment/GDP \\
\hline
\end{tabular}

In expression (4), $\bar{Y}$ is the average value obtained after comparing the total output value of the secondary and tertiary industries in each region for a continuous ten periods of time since 2010, and $i$ or $j$ is the $i$ or $j$ cities.

2.4. Spatial Durbin Model Setting. The spatial Durbin model takes the space lag interpretation variable into account and can use panel data to obtain the spatial spillover effect. Therefore, this paper introduces the lag value YT-1 of the explained variable as the explained variable to study whether financial development can affect industrial agglomeration [33].

The spatial dynamic Durbin model constructed in this paper is as follows:

$$
\begin{aligned}
Y_{i t}= & \tau Y_{i, t-1}+\delta W_{i j} Y_{i, t}+\mu W_{i j} Y_{i, t-1}+\beta X_{i t}+\alpha_{1} \text { Control }_{i t} \\
& +\theta W_{i j} X_{i t}+\alpha_{2} W_{i j} \text { Control }_{i t}+u_{i}+v_{t}+\varepsilon_{i t},
\end{aligned}
$$

where $W_{i}^{j}$ is linked to the spatial weight matrix $W_{i j}^{1}$ and $W_{i j}^{2}$ and $X$ represents the level of financial development $\left(\ln X_{1}\right)$, technological innovation $\left(\ln X_{2}\right)$, and the interaction between financial development and technological innovation $\left(\ln X_{1} \ln X_{2}\right)$. Control represents the control variables of government behavior $\left(Z_{1}\right)$, human capital $\left(Z_{2}\right)$, and capital input level $\left(Z_{3}\right) \cdot u_{i}$ represents the fixed effect of space. $v_{t}$ and $\varepsilon_{i t}$ are separately fixed effect of time as well as the error term.

2.5. Spatial Effect Decomposition. The direct effect is to measure the degree of influence of each unit of change of independent variable on the local dependent variable, and the indirect effect (or spillover effect) is to measure the degree of influence of each unit of change of independent variable on neighboring dependent variable. Because the spatial econometric model studies the complex spatial correlation between variables, the parameters of the model cannot reflect the direct and indirect effects of the function. Therefore, this paper uses the partial differential method to calculate the influence of financial development and technological innovation on industrial agglomeration. We establish the following Durbin model:

$$
Y=(1-\delta W)^{-1}(\beta X+W X \theta)+R
$$

Among them, $W$ represents financial development. $X$ represents technological innovation. $R$ represents the residual term, which is composed of two parts, namely, the intercept term and the error term.

For the $k$-th independent variable $X$, the partial derivative matrix of the expected value of its corresponding $Y$ can be written as

$$
\left[\begin{array}{ccc}
\frac{\partial E(Y)}{\partial x_{1 k}} & \cdots & \frac{\partial(Y)}{\partial x_{n k}}
\end{array}\right]=\left[\begin{array}{ccc}
\frac{\partial E\left(y_{1}\right)}{\partial x_{1 k}} & \cdots & \frac{\partial E\left(y_{1}\right)}{\partial x_{n k}} \\
\vdots & \ddots & \vdots \\
\frac{\partial E\left(y_{n}\right)}{\partial x_{1 k}} & \cdots & \frac{\partial E\left(y_{n}\right)}{\partial x_{n k}}
\end{array}\right]=(I-\delta W)^{-1}\left[\begin{array}{cccc}
\beta_{k} & \omega_{12} \theta_{k} & \cdots & \omega_{1 n} \theta_{k} \\
\omega_{21} \theta_{k} & \beta_{k} & \cdots & \omega_{2 n} \theta_{k} \\
\vdots & \vdots & \vdots & \vdots \\
\omega_{n 1} \theta_{k} & \omega_{n 2} \theta_{k} & \cdots & \beta_{k}
\end{array}\right] .
$$

The average value of the elements on the diagonal of the right partial derivative matrix represents the direct effect. See formula (7) for details. The evaluation of indirect effect comes from the average value of the row sum or column sum of nonformula elements, so as to get the diagonal of the right partial derivative matrix in formula (7).

\section{Empirical Test and Analysis}

This paper uses Stata15.0 to analyze the panel data of 12 provinces in the Beijing-Tianjin-Hebei economic circle, get the results of the autocorrelation test and model regression, and make specific analysis.

3.1. Spatial Autocorrelation Test. Using the panel data of 12 provinces in the Beijing-Tianjin-Hebei region, Moran's I index of industrial agglomeration $(Y)$, financial development $\left(X_{1}\right)$, and technological innovation $\left(X_{2}\right)$ of the BeijingTianjin-Hebei Economic Circle are calculated. Moran's I is a measure of spatial autocorrelation character in multidimensional space. 
In Table 2, the results show that Moran's $I$ index of dependent variable $Y$ is significant at a 5\% level in 2010-2019, and its value fluctuates between 0.10 and 0.17 . Moran's $I$ index of independent variable $X_{1}$ in 2014 and 2016 was significant, if it can meet the requirement of the level of $10 \%$, after comparison, the significance of Moran's I index of other years needs to meet more than $5 \%$, and its value fluctuated between 0.15 and 0.35. In 2015, Moran's I index of independent variable $X_{2}$ was significant if it can meet the requirement of the level of $10 \%$; after comparison, the significance of Moran's I index of other years fluctuated between 0.13 and 0.33 , which can vividly show that a significant spatial positive correlation exists between industrial agglomeration, financial development, and technological innovation in the Beijing-Tianjin-Hebei economic circle.

In order to clearly find the determinants of industrial agglomeration in the Beijing-Tianjin-Hebei economic circle, based on the perspective of spatial correlation, selecting financial development and technological innovation as basic indicators, a Moran's I index change trend chart was produced, through the dependent variable $y$ and independent variables $X_{1}$ and $X_{2}$ to express, and see Figure 1 .

In Figure 1, the industrial agglomeration of the BeijingTianjin-Hebei Economic Circle has a good momentum of development in 2010 for ten consecutive years, and the contribution of industrial added value to the people's GDP has shown an upward trend year by year. Since 2010, the traditional industries in the area have focused on upgrading strategies. They have prompt the development of emerging industries to accelerate further. From 2016 to 2019, industrial upgrading has achieved certain results and new industries have developed more rapidly.

Taking Moran's I index of financial development as the survey object, after an in-depth analysis of its changes, it can be found that the added value of the financial industry in the Beijing-Tianjin-Hebei region has been in a relatively stable state during the three years from 2010, which is mainly reflected in the level of financial development. In the five years since 2014, the added value of the financial industry has shown a downward trend, and the stability of the level of financial development has also been greatly affected. The reason is that the distribution of financial resources in the Beijing-Tianjin-Hebei region is not balanced, and the government inhibits the development of the virtual economy such as real estate, which makes the development of the financial industry slow down. The change of Moran's I index of scientific and technological innovation shows that the number of invention patent applications in the BeijingTianjin-Hebei region is increasing from 2010 to 2019. Scientific and technological innovation overall level shows an upward trend. The reason is that the achievement of the collaborative innovation and development strategy of Beijing-Tianjin-Hebei promote the agglomeration of innovation resource elements and provide support for the technology research.
TABLE 2: Moran's $I$ index test results.

\begin{tabular}{cccc}
\hline Year & $Y$ & $X_{1}$ & $X_{2}$ \\
\hline 2010 & $0.102^{* *}$ & $0.338^{* *}$ & $0.284^{* *}$ \\
2011 & $0.108^{* *}$ & $0.345^{* *}$ & $0.137^{* *}$ \\
2012 & $0.112^{* * *}$ & $0.347^{* *}$ & $0.287^{* *}$ \\
2013 & $0.123^{* * *}$ & $0.335^{* *}$ & $0.296^{* *}$ \\
2014 & $0.125^{* *}$ & $0.196^{*}$ & $0.304^{* *}$ \\
2015 & $0.102^{* *}$ & $0.175^{* *}$ & $0.298^{*}$ \\
2016 & $0.118^{* *}$ & $0.274^{*}$ & $0.301^{* *}$ \\
2017 & $0.132^{* * *}$ & $0.182^{* *}$ & $0.315^{* *}$ \\
2018 & $0.146^{* * *}$ & $0.171^{* *}$ & $0.326^{* *}$ \\
2019 & $0.161^{* * *}$ & $0.156^{* *}$ & $0.322^{* *}$ \\
\hline
\end{tabular}

Note. ${ }^{*},{ }^{* *},{ }^{* *}$, and ${ }^{* *}$ indicate significant differences at $10 \%, 5 \%$, and $1 \%$ test levels, respectively.

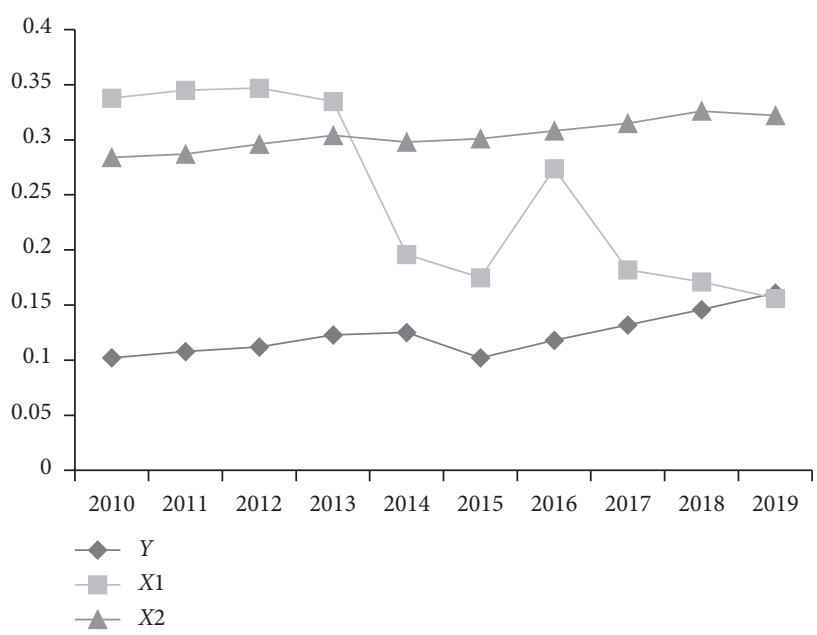

Figure 1: Trend of Moran's I index.

3.2. Analysis of Empirical Results. According to the general idea of studying regional economic problems, this thesis constructed a dynamic space Durbin model; the realization of this goal is mainly by means of different matrix weights; and at the same time, its influence is refined in an all-round way through partial differentiation.

An empirical analysis of the impact of financial development and technological innovation on industrial agglomeration is important. Applying the dynamic spatial Durbin model under the weight of geographical distance, based on two aspects of direction and scale, the subject adopts empirical research methods to deeply investigate the impact of financial development and technological innovation on industrial agglomeration. Please see Table 3 for details.

Based on the empirical results in Table 3 and prerequisites, the following series of studies have been carried out on this subject:

(1) The spillover effect of industrial agglomeration in Beijing-Tianjin-Hebei Economic Circle is significant. In the Durbin model with two spatial matrix 
TABle 3: Empirical results of dynamic spatial Durbin model.

\begin{tabular}{|c|c|c|}
\hline Variable & Geographical distance weight matrix & Economic distance weight matrix \\
\hline \multirow[b]{2}{*}{$Y_{t-1}$} & $0.125^{* * *}$ & $0.143^{* *}$ \\
\hline & $(0.043)$ & $(0.045)$ \\
\hline \multirow{2}{*}{$\ln X_{1}$} & $0.676^{*}$ & 0.269 \\
\hline & $(0.127)$ & $(0.111)$ \\
\hline \multirow{2}{*}{$\ln X_{2}$} & $0.275^{* * *}$ & $0.113^{* *}$ \\
\hline & $(0.049)$ & $(0.053)$ \\
\hline \multirow{2}{*}{$\ln X_{1-} \ln X_{2}$} & $-0.062^{* * *}$ & $-0.022^{* *}$ \\
\hline & $(-0.013)$ & $(-0.011)$ \\
\hline \multirow{2}{*}{$Z_{1}$} & -0.736 & $-0.634^{*}$ \\
\hline & $(-0.301)$ & $(-0.335)$ \\
\hline \multirow{2}{*}{$Z_{2}$} & $1.526^{* * *}$ & $0.537^{*}$ \\
\hline & $(3.014)$ & $(2.667)$ \\
\hline \multirow{2}{*}{$Z_{3}$} & $0.098^{* *}$ & $0.065^{* *}$ \\
\hline & $(0.096)$ & $(0.148)$ \\
\hline \multirow{2}{*}{$W \times Y_{t-1}$} & $0.353^{* *}$ & $0.313^{* *}$ \\
\hline & $(0.151)$ & $(0.145)$ \\
\hline \multirow{2}{*}{$W \times \ln X_{1}$} & $1.307^{* * *}$ & -0.141 \\
\hline & $(0.447)$ & $(-0.212)$ \\
\hline \multirow{2}{*}{$W \times \ln X_{2}$} & $0.604^{* * *}$ & 0.055 \\
\hline & $(0.215)$ & $(0.072)$ \\
\hline \multirow{2}{*}{$W \times \ln X_{1 \_} \ln X_{2}$} & $-0.174^{* * *}$ & $0.127^{* * *}$ \\
\hline & $(-0.059)$ & $(0.053)$ \\
\hline \multirow{2}{*}{$W \times Z_{1}$} & $-2.546^{* *}$ & -0.044 \\
\hline & $(-1.085)$ & $(-0.396)$ \\
\hline \multirow{2}{*}{$W \times Z_{2}$} & $-36.798^{* * *}$ & $-21.406^{* *}$ \\
\hline & $(-9.986)$ & $(-10.127)$ \\
\hline \multirow{2}{*}{$W \times Z_{3}$} & $2.376^{* * *}$ & $1.390^{* * *}$ \\
\hline & $(0.408)$ & $(0.405)$ \\
\hline \multirow{2}{*}{ Spatial rho } & 0.872 & $-0.592^{* * *}$ \\
\hline & $(0.260)$ & $(-0.166)$ \\
\hline$N$ & 120 & 120 \\
\hline Log-likelihood & 99.6653 & 88.3828 \\
\hline$R^{2^{\circ}}$ & 0.826 & 0.783 \\
\hline
\end{tabular}

Note. ${ }^{*},{ }^{* *},{ }^{* *}$, and ${ }^{* *}$ indicate significant differences at $10 \%, 5 \%$, and $1 \%$ test levels, respectively.

weights, the industrial agglomeration coefficient of Beijing-Tianjin-Hebei Economic Circle shows that the coordinated development of the Beijing-TianjinHebei integration plays an important role. In the Durbin model under the weight of geographical distance matrix, the industrial agglomeration of the Beijing-Tianjin-Hebei Economic Circle indicates a positive effect, which indicates that, with the construction and improvement of the transportation network such as expressway and high-speed railway, the transportation integration of the Beijing-TianjinHebei region has been formed. In the Durbin model under the weight of economic distance matrix, the industrial agglomeration of the Beijing-TianjinHebei Economic Circle also indicates that and industrial and economic development are moving towards deep integration.

(2) The industrial agglomeration of Beijing-TianjinHebei Economic Circle has a self-promoting effect. In the spatial Durbin model taking two matrices as the basic weights, the conclusions are drawn: a significant positive relationship exists in the regression coefficient of the industrial agglomeration lag value $\left(Y_{t-1}\right)$ more than $5 \%$ in the level, and the initial industrial agglomeration of the BeijingTianjin-Hebei Economic Circle can directly act on the current industrial agglomeration. The survey shows that the Beijing-Tianjin-Hebei coordinated development strategy has paved the way for the continuous improvement of the industrial chain. The reason for industrial agglomeration is the change of the industrial chain, which can form a good closed loop of self-improvement.

(3) Financial development $\left(\ln X_{1}\right)$ and technological innovation $\left(\ln X_{2}\right)$ have positive effects on industrial agglomeration. Positive can be drawn of coefficient of financial development in the Durbin model under the weight of two spatial matrices. The financial development of Beijing-Tianjin-Hebei Economic Circle $\left(\ln X_{1}\right)$ has a positive effect on industrial agglomeration, but it is only significant in the model under the weight of geographical distance matrix, which is mainly because the real estate, sports economy, and other virtual economies in BeijingTianjin-Hebei region are more active, and finance serves the virtual economy more under the effect of 
profit. However, the development level of the virtual economy represented by real estate has a strong correlation with geographical factors, so the positive impact of the virtual economy on industrial agglomeration is more significant in the model under the weight of geographical distance matrix. The regression coefficient of science and technology innovation $\left(\ln X_{2}\right)$ is positive, which is significant at the level of $5 \%$ in the Durbin model under the two spatial matrix weights, which fully shows that the positive impact exists between technological innovation and industrial agglomeration, and this relationship is significant. This is mainly due to the unified development of industry and technology in the BeijingTianjin-Hebei region to ensure the realization of the goal of industrial chain extension. It can also strive to be at the same level as the level of technological innovation. Technological innovation promotes industrial growth and industrial agglomeration.

(4) Government behavior $\left(Z_{1}\right)$ has no significant impact on industrial agglomeration. The regression coefficient of government behavior $\left(Z_{1}\right)$ is negative in the Durbin model with two spatial matrix weights. The reason for this phenomenon may be that the increase of public financial expenditure will not only improve public welfare such as transportation and education but also produce siphon effect [34], which makes the high-quality resources of industrial development flow from surrounding cities to better central cities, that is, from Hebei to Beijing and Tianjin, which confirms that the negative impact exists between it and the relationship between industrial agglomeration. In the Beijing-Tianjin-Hebei region, the siphon effect is significant in Beijing and Tianjin, so the negative impact exists between state behavior and industrial agglomeration.

(5) The positive impact exists between human capital $\left(Z_{2}\right)$ and the relationship between industrial agglomeration. The regression coefficient of human capital $\left(Z_{2}\right)$ is positive under the two spatial matrix weights, which can be regarded as that human capital enjoys a significant positive impact on industrial agglomeration, which makes the characteristics of talent gathering within the region. Most of the college graduates in the Beijing-Tianjin-Hebei region will choose to work in the school location or nearby provinces and cities, which makes the talent reserve of the Beijing-Tianjin-Hebei region continues to improve and can provide talent and technical support for industrial development and industrial agglomeration

(6) The level of capital investment $\left(Z_{3}\right)$ has a positive impact. The regression coefficient of capital investment level $\left(Z_{3}\right)$ is positive in the Durbin model. There is a significant correlation between the level of capital investment and the ability to serve industrial development. The reason for this phenomenon may be that the level of capital investment can reflect the level of urban infrastructure. The higher the ratio of the two, the more foreign investment will be attracted.

(7) Interaction parameters $\left(\ln X_{1 \_} \ln X_{2}\right)$ have a negative impact on industrial agglomeration. The coefficient of $\ln X_{1} \ln X_{2}$ is negative in the model under the weight of geographical distance matrix; based on the weight of the economic distance matrix, the model is negative and has a significant impact, but it needs to exceed $5 \%$.

Decomposition of the effect on industrial agglomeration. In order to analyze the relationship between regional financial development and technological innovation in this region and other adjacent regions, we need to decompose the impact effect. Because the model under the weight of geographical distance matrix has greater goodness of fit $R^{2}$ and maximum log-likelihood, the model under the weight of geographical distance matrix is chosen.

Based on the decomposition data of spatial effects in Table 4, this paper makes the following analysis:

(1) The parameter of financial development $\left(\ln X_{1}\right)$ and technological innovation $\left(\ln X_{2}\right)$ on industrial agglomeration is analyzed. In both direct and indirect effects, financial development has a significant positive correlation with industrial agglomeration. The index results must be more than $10 \%$ and $5 \%$, respectively, which fully shows that financial development has a significant impact on industrial agglomeration and has different degrees of promotion. And development can directly affect the local and nearby industrial clusters and ultimately promote the continuous development of the latter. The impact of technological innovation on industrial agglomeration is that the industrial development of the Beijing-Tianjin-Hebei Economic Circle has entered the era of industrial chain by adjusting the structure and optimizing the layout.

(2) Interaction parameters $\left(\ln X_{1 \_} \ln X_{2}\right)$ on the impact of industrial agglomeration: the interaction will produce corresponding changes to industrial agglomeration, which is negative at the level of $5 \%$ and $10 \%$. From a comprehensive perspective, if the overall benefit is negative, it needs to meet the index value of more than $10 \%$, which fully shows that a significant negative impact exists on the local and nearby industrial clusters. The bottom line of this situation is that the Beijing-Tianjin-Hebei Economic Circle promotes the development of the virtual economic circle, and at the same time lays the foundation for the generation of the siphon effect, which in turn causes the mutual influence of financial development to industry agglomeration, and this principle also applies to scientific and technological innovation.

(3) Analysis of the effect of control variables on industrial agglomeration: the direct effect of government behavior $\left(Z_{1}\right)$ is not significant when the indirect effect is significantly negative. The overall 
TABle 4: Decomposition of spatial effects.

\begin{tabular}{lccc}
\hline Variable & Direct effect & Indirect effect & Total effect \\
\hline \multirow{2}{*}{$X_{1}$} & $0.419^{*}$ & $0.647^{* *}$ & $0.865^{*}$ \\
& $(0.245)$ & $(0.374)$ & $(0.393)$ \\
$\ln X_{2}$ & $0.118^{* *}$ & $0.147^{* *}$ & $0.215^{* * *}$ \\
& $(0.048)$ & $(0.069)$ & $(0.053)$ \\
$\ln X_{1-} \ln X_{2}$ & $-0.134^{* *}$ & $0.070^{*}$ & $-0.093^{*}$ \\
$Z_{1}$ & $(0.062)$ & $(0.039)$ & $(0.049)$ \\
& -0.827 & $-1.307^{*}$ & $(3.361)$ \\
$Z_{2}$ & $(0.351)$ & $(2.666)$ & 134 \\
& 2.122 & $(3.869)$ & $\left(4.653^{*}\right.$ \\
$Z_{3}$ & $(3.098)$ & $3.529^{*}$ & $\left(4.072^{*}\right.$ \\
& 0.543 & $(1.911)$ & $(3.634)$ \\
\hline
\end{tabular}

Note. ${ }^{*},{ }^{* *},{ }^{* *}$, and ${ }^{* *}$ indicate significant differences at $10 \%, 5 \%$, and $1 \%$ test levels, respectively.

effect is negative. This fully proves that there is a direct and indirect negative correlation between government behavior and industrial agglomeration. The impact of human capital $\left(Z_{2}\right)$ is positive, but not significant. From the perspective of indirect effects and total effects, the result is positive and significant, and a condition needs to be met, that is, the final level of more than $10 \%$, which fully shows that human capital can promote industrial agglomeration. The reasons may be that college students are only potential productivity; it is uneasy to have a direct impact on the industrial agglomeration degree of the Beijing-Tianjin-Hebei Economic Circle. However, most college students in the Beijing-Tianjin-Hebei region will choose the Beijing-Tianjin-Hebei region for employment after graduation, which can affect industrial agglomeration in an indirect way, and it is positive. Although the level of capital investment $\left(Z_{3}\right)$ has direct effects, it cannot be described as significant. The production of positive and indirect benefits and overall effects need to meet the condition of more than $10 \%$, which fully shows that the positive impact exists between capital investment and industrial agglomeration. The bottom line of this phenomenon is that the level of capital investment and the level of industrial infrastructure establishment have a significant positive correlation, which can promote industrial agglomeration. However, with the continuous development of finance and the improvement of technological innovation, the level of fixed capital investment will also increase accordingly, which will help enrich the industrial structure, so it does not have a significant impact at this time and does not apply to industrial agglomeration.

\section{Conclusions and Suggestions}

4.1. Conclusions. This paper constructs the spatial Durbin model to investigate the relationship between financial development, technological innovation, industrial agglomeration, and the development of the Beijing-Tianjin-Hebei Economic Circle. The results are as follows: (1) as an important component of the Beijing-Tianjin-Hebei Economic Circle, financial development and technological innovation can significantly positively affect industrial agglomeration. The impact of financial development on industrial agglomeration is positive under the weight of two spatial matrices but significant only under the weight of the geographical distance matrix. The impact of scientific and technological innovation is significantly positive under the two spatial matrix weights. (2) Government behavior, human capital has a certain impact on industrial agglomeration. In the Durbin model with two spatial matrix weights, the impact of government behavior on industrial agglomeration is negative and not significant. In the Durbin model with two spatial matrix weights, the impact of human capital on industrial agglomeration is positive and significant. The impact of capital input level on industrial agglomeration is positive and significant under the two spatial matrix weights, and the significance also has some differences. (3) The spillover effect of industrial agglomeration in the BeijingTianjin-Hebei Economic Circle is significant, and the selfpromotion effect of industrial agglomeration has been formed. Significant positive and indirect benefits exist in the relationship of the two on industrial agglomeration. The spillover effect of industrial agglomeration is more significant. In addition, the condition that is significantly positive is that the lag value of the first period of industrial agglomeration needs to have an impact of more than $5 \%$ on the current lag value, which fully shows that industrial agglomeration has a self-propelled effect.

4.2. Suggestions. From the above survey results, we can see that financial development and technological innovation can positively affect industrial agglomeration if they can meet certain requirements, but they differ greatly from the perspective of significance. After the two interact, they will affect industrial agglomeration in a negative way. Financial development and technological innovation can promote industrial agglomeration and promote the impact of financial and technological interaction on industrial agglomeration from negative to positive.

(1) Facing the current development status of BeijingTianjin-Hebei, it is necessary to formulate a scientific 
and coordinated development plan, so as to fully demonstrate the spillover effect of regional cooperation. The government should play a role of crossregional coordination, promote the financial service industry in the Beijing-Tianjin-Hebei region while following the objective law of the Beijing-TianjinHebei Economic Circle, further expand the cooperation field, and improve cooperation mechanism.

(2) Fully stimulate the scientific and technological innovation of the Beijing-Tianjin-Hebei Economic Circle. The state should fully understand the important practical significance of scientific and technological innovation, increase support for industrial technology research and development and personnel training, promote technological reform, and realize the cross-regional flow of scientific and technological innovation elements. In addition, the government needs to play a leading role and strengthen cross-regional cooperation.

(3) With the development of the service industry as the goal, we should correctly guide financial development and scientific and technological innovation. A relationship can be easily seen from financial development and scientific and technological innovation. Thus, the government is supposed to promote the combination of financial development and scientific and technological innovation and guide financial enterprises to focus their support.

\section{Data Availability}

The data that provide help for the research of this subject are included in this article.

\section{Conflicts of Interest}

The authors affirm that the publication of this topic does not involve any impact on interest relationships.

\section{Authors' Contributions}

All the authors contributed equally to this paper.

\section{Acknowledgments}

This paper was supported by the doctoral research fund of Anhui University of Finance and Economics (no. 85051).

\section{References}

[1] P. Y. Yang and J. J. Chen, "Research on industrial agglomeration, green development and governance system-based on the survey of industrial agglomeration area in southern Zhejiang," Economic System Reform, vol. 05, pp. 93-100, 2018.

[2] 1890 Marshall, Principles of Economics.

[3] P. Crozet and C. Koenig, The Cohesion vs. Growth Tradeoff: Evidence from EU Regions, University of Paris, Paris, France, 2007.
[4] H. Goot and J. Smit, "Agglomeration, innovation and regional growth: theoretical perspectives and meta-analysis," SSRN Electronic Journal, pp. 256-281, 2009.

[5] M. Sbergami and F. Sbergimi, "Agglomeration and growth: cross-country evidence," Journal of Urban Economics, vol. 65, no. 1, pp. 48-63, 2009.

[6] H. R. Hu and Y. F. Nie, "Industrial agglomeration, industrial structure optimization and enterprise productivity: an empirical study based on national development zones," Contemporary Economic Science, vol. 40, no. 4, pp. 39-47, 2018.

[7] J. R. Tang, Y. X. Fang, X. H. Zhang, and Y. C. Tang, "Research on spatial spillover effect of industrial agglomeration and regional economic growth-based on China's provincial manufacturing spatial Durbin model," Statistics and Information Forum, vol. 33, no. 10, pp. 56-65, 2018.

[8] Q. X. Zhao, C. X. Xia, and J. J. Shi, "Scientific and technological talent agglomeration, industrial agglomeration and regional innovation capability: an empirical analysis based on Beijing Tianjin Hebei, Yangtze river delta and pearl river delta," Research on Science and Technology Management, vol. 39, no. 24, pp. 54-62, 2019.

[9] T. Gehrig, "Cities and the geography of financial centers," Economics of Cities: Theoretical Perspectives, vol. 24, no. 4, p. 24,2004

[10] C. Christopoulos and T. Tsionas, "Financial development and economic growth: evidence from panel unit root and cointegration tests," Journal of Development Economics, vol. 73, no. 1, pp. 55-74, 2004.

[11] J. Palmberg, "Spatial concentration in the financial industry," Ratio Working Paper, no. 18, pp. 4-5, 2012.

[12] M. Michetti, "Financial development and agglomeratio," MPRA Paper, vol. 48425, pp. 1-4, 2013.

[13] Y. S. Li, Y. Q. Lu, and T. Wang, "How does financial support and technological innovation affect export complexity? Empirical research based on China's high tech industry," Foreign Economy and Management, vol. 41, no. 8, pp. 43-57, 2019.

[14] L. J. Si and L. M. Zhang, "The impact of financial agglomeration externality on economic growth: an empirical analysis based on the panel data of provincial capital cities," Economic Longitude and Latitude, vol. 36, no. 3, pp. 150-156, 2019

[15] P. Zhang and W. Yu, "Spatial interaction spillover between financial agglomeration and urban development efficiency: an empirical study based on simultaneous equations of urban space at prefecture level and above," Journal of Shanxi University of Finance and Economics, vol. 41, no. 4, pp. 1-16, 2019.

[16] M. Muller, Innovation Interactions between Knowledge-Intensive Business Services and Small and Medium-Sized Enterprises, Physica-Verlag, Heidelberg, Germany, 2001.

[17] E. Kesidou and H. Romijn, "Do local knowledge spillovers matter for development? An empirical study of Uruguay's software cluster," World Development, vol. 36, no. 10, pp. 2004-2028, 2008.

[18] C. Hornych and M. Schwartz, "Industry concentration and regional innovation performance-empirical evidence for eastern Germany," SPRU Electronic IWH Discussion Paper, vol. 8, 2009.

[19] J. Knoben, "Localized inter-organizational linkages,agglomeration effects, and the innovation performance of firms," The Annals of Regional Science, vol. 43, pp. 757-779, 2012.

[20] Y. R. Cai and H. L. Wang, "Technological innovation, industrial agglomeration and regional labor productivity," Exploration of Economic Problems, vol. 10, pp. 59-69, 2018. 
[21] C. Q. Wu and M. L. Deng, "Scientific and technological innovation, opening up and high quality development of Yangtze river economic belt," Scientific and Technological Progress and Countermeasures, vol. 36, no. 3, pp. 33-41, 2019.

[22] R. Baptista, "Geographical clusters and innovation diffusion," Technological Forecasting and Social Change, vol. 66, no. 1, pp. 31-46, 2001.

[23] J. Amiti, "Location of vertically linked industries: agglomeration versus comparative advantage," European Economic Review, vol. 49, no. 4, pp. 809-832, 2005.

[24] M. Mukim, "Does agglomeration boost innovation? An econometric evaluation," Spatial Economic Analysis, vol. 7, no. 3, pp. 357-380, 2012.

[25] S. Du, J. Feng, and C. Z. Du, "The effect of industrial agglomeration and market concentration on regional innovation capability-based on the comparison of manufacturing industry in Beijing Tianjin Hebei and Yangtze river Delta," Economic and Management Research, vol. 39, no. 7, pp. 48-57, 2018.

[26] G. Ma and E. T. Hofmann, "Population, immigration, and air quality in the USA: a spatial panel study," Population and Environment, vol. 40, no. 3, pp. 283-302, 2019.

[27] Y. J. Hao and S. N. Chen, "Industrial agglomeration, technological innovation and economic growth of urban agglomeration in the middle reaches of the Yangtze river: from the perspective of heterogeneous industrial agglomeration and collaborative agglomeration," Industrial Technology Economy, vol. 38, no. 1, pp. 41-48, 2019.

[28] K. Dong, G. Hochman, X. Kong, R. Sun, and Z. Wang, "Spatial econometric analysis of China's PM10 pollution and its influential factors: evidence from the provincial level," Ecological Indicators, vol. 96, pp. 317-328, 2019.

[29] F. Y. Wang and J. Zheng, "The impact of scientific and technological innovation and financial development on industrial agglomeration: an analysis based on the spatial Durbin model of the Yangtze river economic belt," Scientific and Technological Progress and Countermeasures, vol. 37, no. 13 , pp. 45-53, 2020.

[30] F. Lian and G. F. Zhou, "Institutional arrangement, capital cost and industrial agglomeration: a study from the perspective of spatial economy," Journal of Finance and Economics, vol. 2019, no. 2, pp. 3-11, 2019.

[31] H. J. Wang and Y. Li, "Research on the relationship between added value of financial industry and high quality financial development-based on the perspective of international comparison," Economic Journal, vol. 2018, no. 2, pp. 61-71, 2018.

[32] C. B. Zhong and K. Qian, "Research on logistics industry agglomeration and its influencing factors in Yangtze river economic belt-empirical analysis based on spatial Durbin model," East China Economic Management, vol. 31, no. 5, pp. 78-86, 2017.

[33] J.-B. Liu and S. N. Daoud, "Number of spanning trees in the sequence of some graphs," Complexity, vol. 2019, Article ID 4271783, 22 pages, 2019.

[34] J.-B. Liu, X.-F. Pan, F.-T. Hu, and F.-F. Hu, "Asymptotic Laplacian-energy-like invariant of lattices," Applied Mathematics and Computation, vol. 253, no. 253, pp. 205-214, 2015. 